\title{
Incidence and Risk of Severe Neutropenia in Advanced Cancer Patients Treated with Cetuximab \\ A Meta-Analysis
}

Long Wang, ${ }^{1}$ Yi-zhi Chen, ${ }^{2}$ Duo Shi, ${ }^{3}$ Xue-yin Shi, ${ }^{4}$ Zui Zou ${ }^{4}$ and Jian-hua Zhao ${ }^{5}$

1 Company of Anesthesiology, Second Military Medical University, Shanghai, People's Republic of China

2 Company 10, Second Military Medical University, Shanghai, People's Republic of China

3 Department of Biochemical Pharmacy, School of Pharmacy, Second Military Medical University, Shanghai, People's Republic of China

4 Department of Anesthesiology, Changzheng Hospital, Second Military Medical University, Shanghai, People's Republic of China

5 Physical Examination Centre, the Jinan General Hospital of People's Liberation Army, Jinan, People's Republic of China

\section{Abstract}

Background and Aim: Neutropenia is a serious adverse event for patients who are treated with cetuximab, an inhibitor of endothelial growth factor receptor. However, there is no consistent result of the relationship between cetuximab and neutropenia in randomized controlled trials (RCTs). We did a systematic review and meta-analysis of published RCTs to assess the overall risk of neutropenia associated with cetuximab.

Methods: PubMed, Cochrane Central Register of Controlled Trials, EMBASE, and American Society of Clinical Oncology conferences were searched for relevant RCTs. Quantitative and qualitative analyses were carried out to evaluate the association between neutropenia and cetuximab. Both the fixed-effect model and random-effects model were used.

Results: A total of 7186 patients with a variety of advanced cancers from 14 trials were included in our analysis. The overall incidence of neutropenia in patients receiving cetuximab was $33 \%$ (95\% CI 26, 43). Patients treated with cetuximab had a significantly increased risk of neutropenia compared with patients treated with control medication, with a relative risk (RR) of 1.12 (95\% CI 1.05, 1.19; fixed-effect model). Risk varied with tumor type. Higher risks were observed in patients with colorectal carcinoma (RR 1.17; 95\% CI 1.04, 1.32; fixed-effect model) and non-small cell lung cancer (RR 1.07; 95\% CI 0.99, 1.16; fixed-effect model).

Conclusion: Cetuximab is associated with a significant risk of neutropenia in patients with advanced cancer receiving concurrent chemotherapy. 


\section{Introduction}

The endothelial growth factor receptor (EGFR), presented in many cell types, is a transmembrane protein consisting of an extracellular binding domain, a hydrophobic transmembrane segment, and a cytoplasmic tyrosine kinase domain, and it can be considered as one of the best characterized ligandreceptor systems. ${ }^{[1]}$ The overexpression of EGFR has been found in a variety of solid tumors ${ }^{[2]}$ and endothelial growth factor (EGF) has played a crucial role in disease progression, poor prognosis, and reduced sensitivity to chemotherapy. ${ }^{[3]}$ Therefore blocking the signaling of EGF has been a major focus of new cancer therapeutics.

Cetuximab is a human-murine monoclonal antibody directed against EGFR protein, which is expressed on the surface of human tumor cells. ${ }^{[4]} \mathrm{It}$ was approved by the US FDA for use in metastatic colorectal cancer in February 2004, ${ }^{[5]}$ and first gained approval in Europe for use in the treatment of EGFR-expressing metastatic colorectal cancer following failure of irinotecan-containing regimens. ${ }^{[6]}$ More recently, a meta-analysis demonstrated an improved overall survival in non-small cell lung cancer patients receiving chemotherapy plus cetuximab compared with chemotherapy alone. ${ }^{[7]}$ The clinical efficacy of cetuximab in many other malignancies, such as head and neck cancer and pancreatic cancer, is also currently undergoing extensive evaluation.

With the use of cetuximab, substantial adverse events have been observed. Rash, diarrhea, fatigue, neutropenia, hypertension, nausea, infusion-related or hypersensitivity reactions, and hand-foot skin reactions were very common when cetuximab was administrated for advanced cancer. ${ }^{[8]}$ In addition, recently, a new adverse event (posterior reversible leukoencephalopathy), which is potentially lifethreatening, has been found. Reversible posterior leukoencephalopathy syndrome, of which clinical symptoms include headache, decreased alertness, and mental abnormalities, is a disorder with typical radiologic findings in the posterior regions of the cerebral hemisphere and cerebellum. ${ }^{[9]}$ Neutropenia is the most common dose-limiting toxicity of myelosuppressive chemotherapy and has been found in $51 \%$ of patients who were treated for lymphoma or solid tissue malignancy. ${ }^{[10]}$ Neutropenia also puts patients at high risk of infection, which can be lifethreatening. ${ }^{[11]}$ However, there is no consistent result of the relationship between cetuximab and neutropenia in randomized controlled trials (RCTs). For example, significant association between cetuximab and neutropenia has been established in the studies reported by Burtness et al. ${ }^{[12]}$ and Rosell et al., ${ }^{[13]}$ while Bokemeyer et al. ${ }^{[14]}$ and Borner et al. ${ }^{[15]}$ reported that there was no significant association between cetuximab and neutropenia. Thus, we undertook a systematic review of the relevant RCTs to evaluate the risk of neutropenia associated with cetuximab treatment for advanced cancer.

\section{Methods}

\section{Data Source}

An extensive search of PubMed (from May 1996 to March 2011), Cochrane Central Register of Controlled Trials (from Cochrane Library Issue 1, 2001 to Cochrane Library Issue 3, 2011), and EMBASE (from October 1997 to March 2011) was performed to identify relevant RCTs for our metaanalysis (the detailed search strategy can be found in the supplemental digital content, http://links. adisonline.com/DRZ/A5). Abstracts and virtual meeting presentations from the American Society of Clinical Oncology conferences held between January 2000 and March 2011 were also searched for relevant RCTs. We also searched the reference lists of articles, reviews, letters to the editor, and case reports to find those not yet included in the computerized databases. The language of the research papers was not restricted.

\section{Study Selection}

RCTs that directly compared advanced cancer patients treated with and without cetuximab, respectively, were selected for our analysis. Phase I and single-arm phase II trials were excluded due to the lack of control groups. Specifically, clinical trials that met the following criteria were included in the meta-analysis: (i) prospective phase II and phase III RCTs in patients with advanced cancer; (ii) random assignment of participants to 
cetuximab treatment or control group (placebo or best supportive care) in addition to concurrent chemotherapy and/or treatment with a biological agent; and (iii) available data, including events or incidences of neutropenia and sample size for analysis.

\section{Data Extraction}

Two researchers (LW and YC) extracted data from each identified trial independently in a predesigned review form. The following data were included: authors of each study, publication year, trial design, number of patients, number of patients eligible for neutropenia evaluation, age, sex, intervention, dose of cetuximab administered, cancer type, phase of trial, follow-up time, allocation concealment, blinded analysis, and events or incidences of grade 3 or 4 neutropenia.

\section{Qualitative Assessment}

The studies were appraised independently by two authors (LW and YC) based on the standard criteria (randomization, blinding, loss to followup, and generation of allocation concealment), and additional quantitative quality was assessed using the scoring system developed by Jaded et al., ${ }^{[16]}$ appropriately modified according to the treatments under study. The quality scoring system was as follows: (i) adequacy of randomization appropriate with detailed description of randomization (score 2), randomized but details not reported (score 1), inappropriate randomization (score 0); (ii) allocation concealment - properly used (score 2), unclear (score 1), not used (score 0 ); (iii) blinded method - double blind (score 2), single-blind (score 1), and open-label or unclear (score 0); and (iv) drop-outs and follow-ups - data given (score 1), and data not given (score 0). Any disagreement was resolved by discussion.

\section{Clinical Endpoints}

The primary endpoint was the incidence of neutropenia. Neutropenia in these studies were assessed and recorded according to Common Terminology Criteria for Adverse Events (version
2 or 3$).^{[17,18]}$ For this study, severe neutropenia was defined as grade 3 or above neutropenia.

\section{Statistical Analysis}

Stata v10.0 software (StataCorp, College Station, TX, USA) was used for statistical analysis. We calculated the incidence of neutropenia by using the number of patients with neutropenia in the cetuximab group and total number of patients receiving cetuximab treatment. The proportion of patients with neutropenia was calculated and the $95 \%$ confidence interval was derived for each trial. Relative risk (RR) is the ratio of the risk of an event in the two groups. Odds ratio is the ratio of the odds of an event. Difference in means is a standard statistic that measures the absolute difference between the mean values in the two groups in a clinical trial. RR is applicable to all kinds of data, while odds ratio is only applicable to events of small incidence; thus, the RR was adopted. A subgroup analysis according to tumor type was performed.

We used the chi-square test of heterogeneity and the $\mathrm{I}^{2}$ measure of inconsistency to assess the heterogeneity between trials. With an $\mathrm{I}^{2}$ value larger than $50 \%$ indicating significant heterogeneity, the following techniques were used to explain it: (i) subgroup analysis; (ii) sensitivity analysis performed by excluding the trials that potentially biased the results; and (iii) the randomeffects model was used after efforts were made to explore the cause of the heterogeneity. The Begg's test was used to determine the presence of publication bias regarding our primary variable (RR of neutropenia). A two-tailed $p$-value of $<0.05$ was considered statistically significant.

\section{Results}

A total of 155 clinical studies relevant to cetuximab were identified by our literature search. Review articles, case reports, meta-analyses, observational studies $(\mathrm{n}=48)$, phase I studies $(n=14)$, single-arm phase II studies $(n=20)$, duplicates $(n=16)$, studies in which both control and treatment groups received cetuximab $(n=28)$, and those data not adequate for assessment of severe 


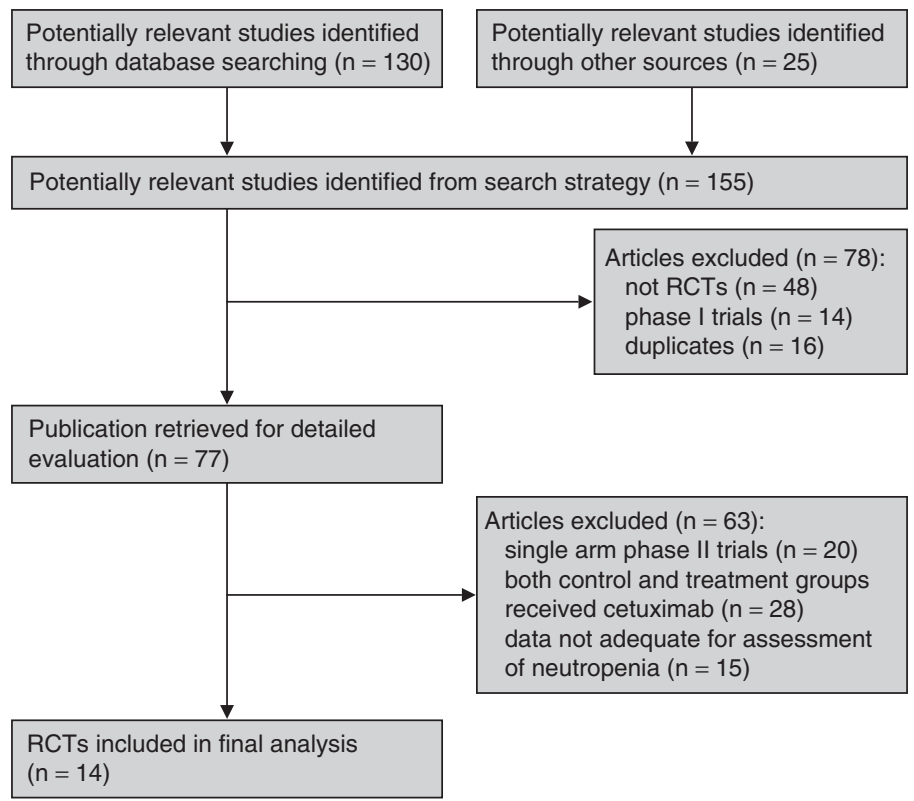

Fig. 1. Selection process for RCTs included in the meta-analysis. $\mathbf{R C T}=$ randomized controlled trial.

neutropenia $(n=15)$ [figure 1] were excluded. Ultimately, 14 RCTs, including six phase II and eight phase III studies, were selected for analysis, involving 7186 patients. The main characteristics (type of study design, underlying malignancy of included patients, concurrent treatment, number of patients, and follow-up time) of the 14 included RCTs are presented in table I. Randomized treatment allocation sequences were generated in all trials. Only one trial was double-blinded and placebo-controlled, ${ }^{[12]}$ two other trials were singleblinded, ${ }^{[15,28]}$ nine of the trials were openlabel, ${ }^{[13,14,20-24,26,27]}$ and the two remaining trials were not specified. ${ }^{[19,25]}$ All trials reported the number and reason of withdrawals and drop-outs. None of the trials mentioned allocation concealment. Thirteen trials were described as multicenter trials, and one did not mention it. ${ }^{[19]}$ The median follow-up time for 13 studies $^{[12-15,20-28]}$ ranged from 8 to 32 months, with one not mentioned. Neutropenia was assessed and recorded according to the National Cancer Institute's common toxicity criteria version 2 or $3 .^{[17,18]}$ The baseline Eastern Cooperative Oncology Group (ECOG) performance status of most patients was between 0 and 2 .
Only one patient's ECOG performance status was 3. ${ }^{[20]}$ Patients were required to have adequate hepatic, renal, and hematologic function. Underlying malignancies were colorectal cancer (five studies), non-small cell lung cancer (four studies), pancreatic cancer (two studies), head and neck cancer (two studies), and squamous cell carcinoma of the esophagus (one study).

Both the fixed-effect and random-effects models were used $\left(I^{2}=40.7 \% ; p=0.057\right)$. The overall RRs of severe neutropenia with cetuximab versus control were 1.12 (95\% CI 1.05, 1.19; $p=0.001$; fixedeffect model [figure 2]) and 1.14 (95\% CI 1.03, 1.25; $\mathrm{p}=0.001$; random-effects model), indicating significantly higher incidence of neutropenia in cetuximab groups. The RRs of subgroup analysis suggested a significant association between severe neutropenia and cetuximab treatment among patients with colorectal cancer (RR 1.17; 95\% CI 1.04, 1.32; fixed-effect model [figure 2]: and RR 1.16; 95\% CI 1.00, 1.34; random-effects model). Numerically increased incidence associated with cetuximab was found in patients with non-small cell lung cancer, with RRs of 1.07 (95\% CI 0.99, 1.16; fixed-effect model) and 1.11 (95\% CI 0.97, 1.28; 
random-effects model), but no statistical difference was found. The RRs of severe neutropenia were lowest in patients with pancreatic cancer treated with cetuximab compared with controls (RR 1.02; 95\% CI 0.79, 1.31; fixed-effect model: and RR 1.06; 95\% CI 0.72, 1.55; random-effects model), and highest in patients with squamous cell carcinoma of the esophagus (RR 1.64; 95\% CI 0.53, 5.04; fixed-effect model: and RR 1.64; 95\% CI 0.53, 5.04; random-effects model). Nine of 14 trials reported that the cetuximab groups had a higher incidence of severe neutropenia compared with the control groups, while four trials showed lower and one trial equal incidences of severe neutropenia (figure 3 ).

The overall incidence of severe neutropenia in patients receiving cetuximab was $33 \%(95 \%$ CI $26,43)$. Patients with different tumors might be at different risks of severe neutropenia due to differences in tumor malignancy and associated treatment. We explored whether having a specific type of cancer is associated with a higher risk of severe neutropenia compared with other cancers. As shown in table II, the risk of severe neutropenia varied according to tumor type. The highest incidence of severe neutropenia was found in

Table I. Characteristics of randomized controlled clinical trials included in the meta-analysis

\begin{tabular}{|c|c|c|c|c|c|c|c|c|}
\hline Study & $\begin{array}{l}\text { Trial } \\
\text { phase }\end{array}$ & $\begin{array}{l}\text { No. of } \\
\text { patients } \\
\text { enrolled }\end{array}$ & $\begin{array}{l}\text { No. of } \\
\text { patients } \\
\text { for analysis }\end{array}$ & $\begin{array}{l}\text { Underlying } \\
\text { malignancy }\end{array}$ & $\begin{array}{l}\text { Concurrent } \\
\text { treatment }\end{array}$ & $\begin{array}{l}\text { Jaded } \\
\text { score }\end{array}$ & $\begin{array}{l}\text { Cetuximab } \\
\text { dose }\left(\mathrm{mg} / \mathrm{m}^{2}\right. \\
\text { per week })\end{array}$ & $\begin{array}{l}\text { Follow-up } \\
\text { time (mo) }\end{array}$ \\
\hline Philip et al. ${ }^{[19]}$ & III & 743 & 716 & Pancreatic cancer & Gemcitabine & 3 & 250 & 27 \\
\hline Lynch et al. ${ }^{[20]}$ & III & 676 & 645 & $\begin{array}{l}\text { Non-small cell lung } \\
\text { cancer }\end{array}$ & $\begin{array}{l}\text { Paclitaxel or } \\
\text { docetaxel }\end{array}$ & 3 & 250 & 22 \\
\hline Lorenzen et al. ${ }^{[21]}$ & II & 66 & 62 & $\begin{array}{l}\text { Squamous cell } \\
\text { carcinoma of the } \\
\text { esophagus }\end{array}$ & $\begin{array}{l}\text { Cisplatin and } \\
\text { fluorouracil }\end{array}$ & 3 & 250 & 24 \\
\hline Pirker et al. ${ }^{[22]}$ & III & 1125 & 1110 & $\begin{array}{l}\text { Non-small cell lung } \\
\text { cancer }\end{array}$ & $\begin{array}{l}\text { Cisplatin and } \\
\text { vinorelbine }\end{array}$ & 4 & 250 & 15 \\
\hline Van Cutsem et al. ${ }^{[23]}$ & III & 1202 & 1202 & Colorectal cancer & $\begin{array}{l}\text { Leucovorin and } \\
\text { fluorouracil }\end{array}$ & 3 & 250 & 16 \\
\hline Adams et al. ${ }^{[24]}$ & III & 804 & 804 & Colorectal cancer & $\begin{array}{l}\text { Leucovorin, } \\
\text { oxaliplatin and } \\
\text { fluorouracil or } \\
\text { oxaliplatin and } \\
\text { capecitabine }\end{array}$ & NA & 250 & 16 \\
\hline Bokemeyer et al.. ${ }^{[14]}$ & II & 338 & 338 & Colorectal cancer & $\begin{array}{l}\text { Fluorouracil, } \\
\text { leucovorin and } \\
\text { oxaliplatin }\end{array}$ & 3 & 250 & 8 \\
\hline Vermorken et al..[25] & III & 442 & 434 & $\begin{array}{l}\text { Head and neck } \\
\text { cancer }\end{array}$ & $\begin{array}{l}\text { Fluorouracil and } \\
\text { cisplatin or } \\
\text { carboplatin }\end{array}$ & 4 & 250 & 12 \\
\hline Sobrero et al. ${ }^{[26]}$ & III & 1298 & 1267 & Colorectal cancer & Irinotecan & 3 & 250 & 32 \\
\hline Borner et al. ${ }^{[15]}$ & II & 74 & 74 & Colorectal cancer & $\begin{array}{l}\text { Capecitabine and } \\
\text { oxaliplatin }\end{array}$ & 4 & 250 & 16 \\
\hline Butts et al. ${ }^{[27]}$ & II & 131 & 130 & $\begin{array}{l}\text { Non-small cell lung } \\
\text { cancer }\end{array}$ & $\begin{array}{l}\text { Cisplatin or } \\
\text { carboplatin }\end{array}$ & 3 & 250 & NA \\
\hline Cascinu et al. ${ }^{[28]}$ & II & 84 & 84 & Pancreatic cancer & $\begin{array}{l}\text { Gemcitabine and } \\
\text { cisplatin }\end{array}$ & 5 & 250 & 16 \\
\hline Rosell et al. ${ }^{[13]}$ & II & 86 & 85 & $\begin{array}{l}\text { Non-small cell lung } \\
\text { cancer }\end{array}$ & $\begin{array}{l}\text { Cisplatin and } \\
\text { vinorelbine }\end{array}$ & 3 & 250 & 15 \\
\hline Burtness et al. ${ }^{[12]}$ & III & 117 & 116 & $\begin{array}{l}\text { Head and neck } \\
\text { cancer }\end{array}$ & $\begin{array}{l}\text { Cisplatin or } \\
\text { placebo }\end{array}$ & 5 & 125 & 24 \\
\hline
\end{tabular}




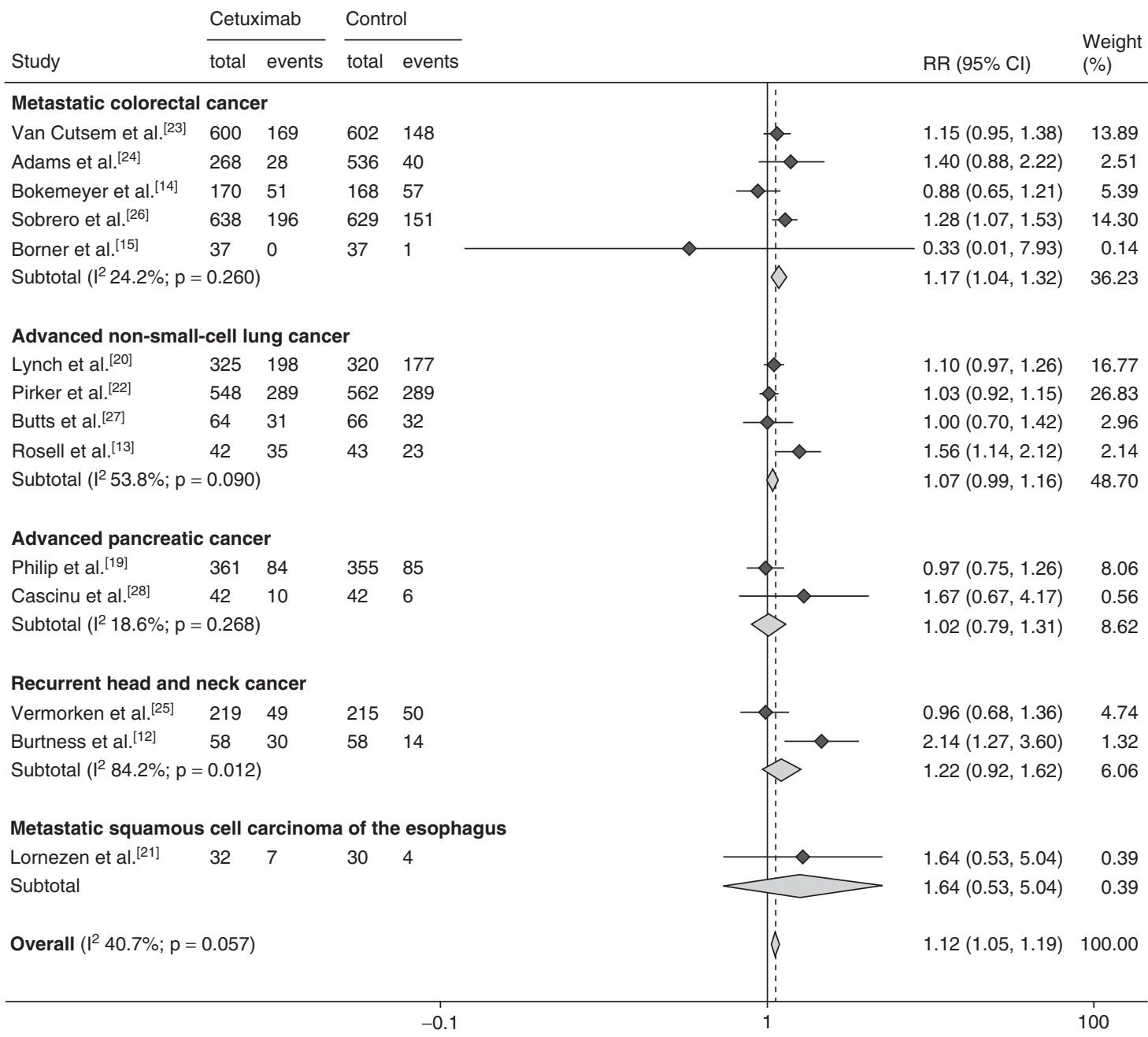

Fig. 2. Relative risk (RR) of neutropenia associated with cetuximab treatment compared with control treatment. An RR $<1$ means a numerically lower incidence than control chemotherapy and an $\mathrm{RR}>1$ means a numerically higher incidence than control chemotherapy. If the lower value of the $95 \% \mathrm{Cl}$ range is greater than 1, it means that there is a statistically significant difference between the two groups. Conversely, a value of 1 or smaller indicates non-significance.

patients with non-small cell lung cancer (61\%; 95\% CI 50, 74), while the lowest incidence was seen in patients with squamous cell carcinoma of the esophagus $(22 \%$; $95 \%$ CI 11,45$)$.

No publication bias was detected for the primary variable of this study (RR of severe neutropenia) by the Begg's or Egger's tests (Begg's test, $p=0.38$; Egger's test, $p=0.29$ ). As shown in figure 4 , the shapes of the funnel plots appeared symmetrical in all comparisons, indicating the absence of publication bias.

\section{Discussion}

Caner patients have an increased susceptibility to severe infections, especially when receiving chemotherapy. Bodey et al. ${ }^{[29]}$ reported that the most important factor contributing to the increasing infection risk is an absolute neutrophil count of $<0.5 \times 10^{9} / \mathrm{L}$. In the RCTs discussing the association of neutropenia and cetuximab, an individual RCT is not powered to detect a significant relationship, so the contribution of 


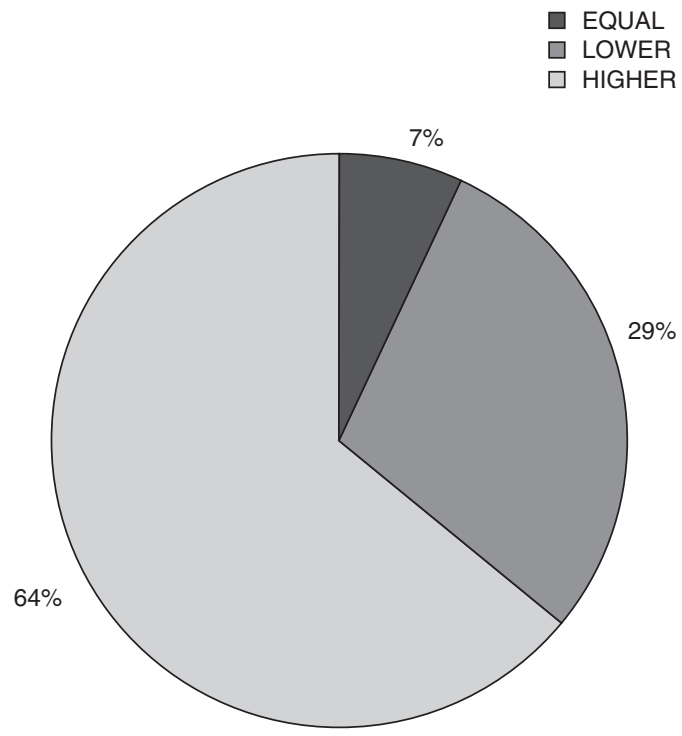

Fig. 3. Comparison of incidence between cetuximab groups and control groups. $64 \%$ of all included trials reported patients treated with cetuximab had a numerically higher incidence of neutropenia, while $29 \%$ were lower, and $7 \%$ were equal.

cetuximab to the development of neutropenia is difficult to assess in one RCT. Thus, we combined 14 RCTs to overcome this limitation. The result showed a high incidence of severe neutropenia $(33 \% ; 95 \%$ CI 26, 43) associated with cetuximab treatment for advanced cancer. Cetuximab treatment had a higher risk of severe neutropenia compared with control (RR 1.12; 95\% CI 1.05, 1.19).

Multiple distinct mechanisms could be involved in the pathogenesis of the severe cetuximabassociated neutropenia. The relationship between cetuximab and neutropenia might be related to a direct myelosuppression. EGF and the
EGF-like protein family play an important role both in physiologic processes, such as cell proliferation and differentiation, and wound healing. ${ }^{[30-32]}$ Cetuximab, which targets EGFR, might inhibit the proliferation of neutrophil through blocking the singling pathway of EGFR. Furthermore, it has been described that EGF enhances tumor necrosis factor (TNF)- $\alpha$-induced activation in human neutrophils, ${ }^{[33]}$ and $\mathrm{TNF} \alpha$ is an important inflammatory mediator to activate neutrophils.

This study also showed that the risk of severe neutropenia with cetuximab can vary with tumor type. The risk was significantly increased in patients with advanced colorectal cancer who received cetuximab. Therefore, more attention should be paid to patients with advanced colorectal cancer when cetuximab-based therapy is used. Patients with advanced non-small cell lung cancer had the highest incidence of severe neutropenia, although there was no significant difference comparing cetuximabbased therapy with control treatment. Cetuximabbased therapy had a tendency to significantly increase the incidence of severe neutropenia when given to patients with advanced non-small cell lung cancer. One of the reasons that non-small cell lung cancer patients had the highest incidence of severe neutropenia might be that current chemotherapies used for non-small cell lung cancer patients have the most serious myelosuppression. Another reason may be the complicated nature of non-small cell lung cancer.

Several limitations of our analysis are worth considering. Firstly, with every meta-analysis, results are affected by the clinical heterogeneity. These trials have different patient clinical profiles, concurrent chemotherapies, lengths of follow-up, and lengths of treatment, so differences among trials

Table II. Incidence of neutropenia with cetuximab among patients with various tumor types

\begin{tabular}{lcccc}
\hline Tumor type & No. of studies & $\begin{array}{l}\text { No. of cetuximab events } \\
\text { (sample size) }\end{array}$ & $\begin{array}{l}\text { No. of control events } \\
\text { (sample size) }\end{array}$ & $\begin{array}{l}\text { Incidence } \\
(95 \% \mathrm{Cl})\end{array}$ \\
\hline Overall & 14 & $1177(3451)$ & $1077(3735)$ & $0.33(0.26,0.43)$ \\
Colorectal cancer & 5 & $444(1723)$ & $397(1993)$ & $0.23(0.17,0.31)$ \\
Non-small cell lung cancer & 4 & $553(1003)$ & $521(1015)$ & $0.61(0.50,0.74)$ \\
Pancreatic cancer & 2 & $94(413)$ & $91(414)$ & $0.23(0.19,0.28)$ \\
Head and neck cancer & 2 & $79(279)$ & $64(280)$ & $0.34(0.15,0.77)$ \\
Squamous cell carcinoma of the esophagus & 1 & $7(33)$ & $4(33)$ & $0.22(0.11,0.45)$ \\
\hline
\end{tabular}




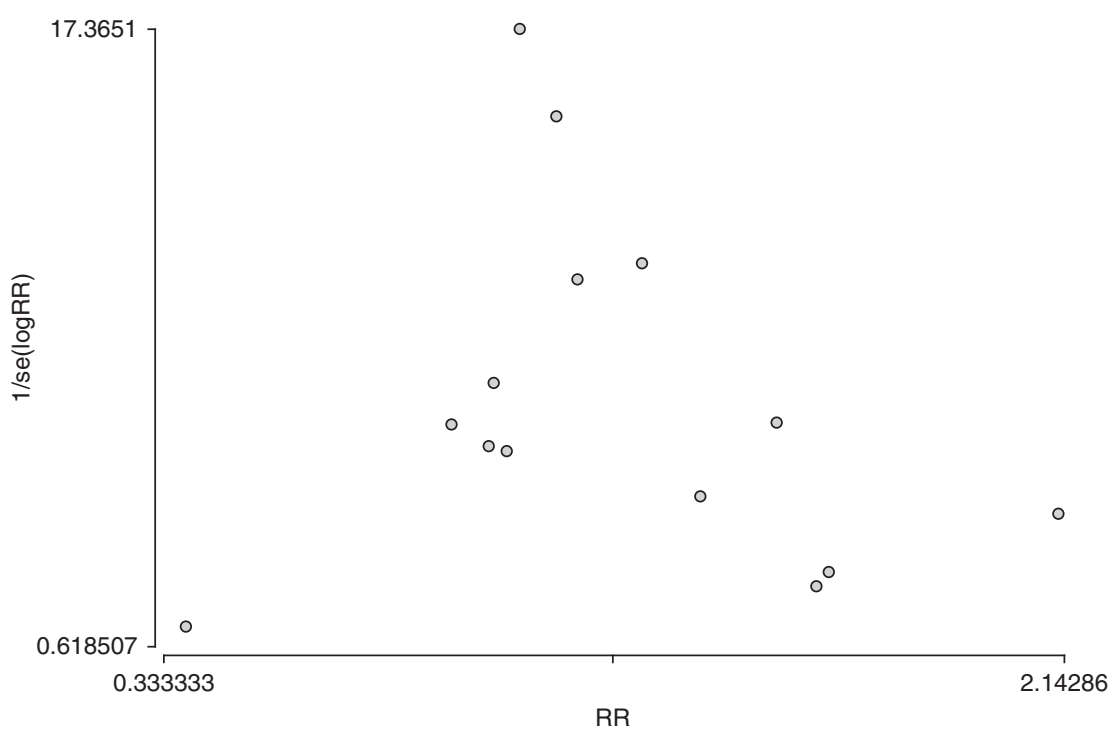

Fig. 4. Funnel plot analysis to detect publication bias. $\mathbf{R R}=$ relative risk; $\mathbf{s e}=$ standard error.

are inevitable, and there is always some heterogeneity, even within individual trials. However, heterogeneity does not necessarily preclude pooling of the results because individual patients are only directly compared with other patients within the same trial and not across the trials. ${ }^{[34,35]}$ Given this uncertainty resulting from clinical heterogeneity, we performed subgroup analysis in our meta-analysis. Secondly, our meta-analysis only included 14 studies of 155 identified in our research. In this regard, we selected only those trials conducted with a rigorous methodology in order to provide solid conclusions. Indeed, meta-analyses often include small numbers of studies, and heterogeneity is therefore a necessary consequence. Higgins et al. ${ }^{[36]}$ evaluated 39 Cochrane reviews and found that $67 \%$ of them included five studies and $20 \%$ included ten studies. A lower threshold for the number of studies to be included in a meta-analysis has not yet been established.

As almost all the studies included in this analysis used the same doses of cetuximab, future studies are recommended to investigate whether a higher dose of cetuximab has higher risk of neutropenia. The risk of neutropenia was significantly increased in patients with advanced colorectal cancer who received cetuximab, there- fore, it is important to explore how to prevent neutropenia in advanced colorectal cancer patients. Patients with advanced non-small cell lung cancer had the highest incidence of severe neutropenia, although there was no significant difference comparing cetuximab-based therapy with control treatment, so more studies are needed to find out the reason why patients with advanced non-small cell lung cancer had the highest incidence of severe neutropenia. More RCTs that include the first-line drugs with or without cetuximab are recommended.

In conclusion, our data have shown that cetuximab is associated with a significant risk of neutropenia in patients with advanced cancer receiving concurrent chemotherapy. The risk varies with tumor type and a higher risk is seen in patients with colorectal cancer and non-small cell lung cancer. Early monitoring and effective treatment of neutropenia is important for patients who receive cetuximab-based therapy.

\section{Acknowledgments}

Long Wang, Yi-zhi Chen, and Duo Shi contributed equally to this article. All the authors declared no potential conflict of interest and no funding was received. 


\section{References}

1. Milano G, Spano JP, Leyland-Jones B. EGFR-targeting drugs in combination with cytotoxic agents: from bench to bedside, a contrasted reality. Br J Cancer 2008; 99 (1): 1-5

2. Heist RS, Christiani D. EGFR-targeted therapies in lung cancer: predictors of response and toxicity. Pharmacogenomics 2009; 10 (1): 59-68

3. Brandes AA, Franceschi E, Tosoni A, et al. Epidermal growth factor receptor inhibitors in neuro-oncology: hopes and disappointments. Clin Cancer Res 2008; 14 (4): 957-60

4. Reynolds NA, Wagstaff AJ. Cetuximab: in the treatment of metastatic colorectal cancer. Drugs 2004; 64 (1): 109-18; discussion 119-121

5. Cunningham D, Humblet $\mathrm{Y}$, Siena S, et al. Cetuximab monotherapy and cetuximab plus irinotecan in irinotecanrefractory metastatic colorectal cancer. N Engl J Med 2004; 351 (4): $337-45$

6. Ocvirk J, Brodowicz T, Wrba F, et al. Cetuximab plus FOLFOX6 or FOLFIRI in metastatic colorectal cancer: CECOG trial. World J Gastroenterol 2010; 16 (25): 3133-43

7. Chen P, Wang L, Liu B, et al. EGFR-targeted therapies combined with chemotherapy for treating advanced nonsmall-cell lung cancer: a meta-analysis. Eur J Clin Pharmacol 2011; 67 (3): 235-43

8. Dubey S, Schiller JH. Three emerging new drugs for NSCLC: pemetrexed, bortezomib, and cetuximab. Oncologist 2005; 10 (4): 282-91

9. Palma JA, Gomez-Ibañez A, Martin B, et al. Nonconvulsive status epilepticus related to posterior reversible leukoencephalopathy syndrome induced by cetuximab. Neurologist 2011; 17 (5): 273-5

10. Blay JY, Chauvin F, Le Cesne A, et al. Early lymphopenia after cytotoxic chemotherapy as a risk factor for febrile neutropenia. J Clin Oncol 1996; 14 (2): 636-43

11. Crawford J, Dale DC, Lyman GH. Chemotherapy-induced neutropenia: risks, consequences, and new directions for its management. Cancer 2004; 100 (2): 228-37

12. Burtness B, Goldwasser MA, Flood W, et al. Phase III randomized trial of cisplatin plus placebo compared with cisplatin plus cetuximab in metastatic/recurrent head and neck cancer: an Eastern Cooperative Oncology Group study. J Clin Oncol 2005; 23 (34): 8646-54

13. Rosell R, Robinet G, Szczesna A, et al. Randomized phase II study of cetuximab plus cisplatin/vinorelbine compared with cisplatin/vinorelbine alone as first-line therapy in EGFR-expressing advanced non-small-cell lung cancer. Ann Oncol 2008; 19 (2): 362-9

14. Bokemeyer C, Bondarenko I, Makhson A, et al. Fluorouracil, leucovorin, and oxaliplatin with and without cetuximab in the first-line treatment of metastatic colorectal cancer. J Clin Oncol 2009; 27 (5): 663-71

15. Borner M, Koeberle D, Von Moos R, et al. Adding cetuximab to capecitabine plus oxaliplatin (XELOX) in first-line treatment of metastatic colorectal cancer: a randomized phase II trial of the Swiss Group for Clinical Cancer Research SAKK. Ann Oncol 2008; 19 (7): 1288-92

16. Jadad AR, Moore RA, Carroll D, et al. Assessing the quality of reports of randomized clinical trials: is blinding necessary? Control Clin Trials 1996; 17 (1): 1-12
17. Okayama N, Nishioka M, Hazama S, et al. The importance of evaluation of DNA amplificability in KRAS mutation testing with dideoxy sequencing using formalin-fixed and paraffin-embedded colorectal cancer tissues. Jpn J Clin Oncol 2011; 41 (2): 165-71

18. $\mathrm{Wu} \mathrm{L}$, Parton $\mathrm{A}, \mathrm{Lu} \mathrm{L}$, et al. Lenalidomide enhances antibody-dependent cellular cytotoxicity of solid tumor cells in vitro: influence of host immune and tumor markers. Cancer Immunol Immunother 2011; 60 (1): 61-73

19. Philip PA, Benedetti J, Corless CL, et al. Phase III study comparing gemcitabine plus cetuximab versus gemcitabine in patients with advanced pancreatic adenocarcinoma: Southwest Oncology Group-directed intergroup trial S0205. J Clin Oncol 2010; 28 (22): 3605-10

20. Lynch TJ, Patel T, Dreisbach L, et al. Cetuximab and first-line taxane/carboplatin chemotherapy in advanced non-small-cell lung cancer: results of the randomized multicenter phase III trial BMS099. J Clin Oncol 2010; 28 (6): 911-7

21. Lorenzen S, Schuster T, Porschen R, et al. Cetuximab plus cisplatin-5-fluorouracil versus cisplatin-5-fluorouracil alone in first-line metastatic squamous cell carcinoma of the esophagus: a randomized phase II study of the Arbeitsgemeinschaft Internistische Onkologie. Ann Oncol 2009; 20 (10): 1667-73

22. Pirker R, Pereira JR, Szczesna A, et al. Cetuximab plus chemotherapy in patients with advanced non-small-cell lung cancer (FLEX): an open-label randomised phase III trial. Lancet 2009; 373 (9674): 1525-31

23. Van Cutsem E, Kohne CH, Hitre E, et al. Cetuximab and chemotherapy as initial treatment for metastatic colorectal cancer. N Engl J Med 2009; 360 (14): 1408-17

24. Adams RA, Meade AM, Madi A, et al. Toxicity associated with combination oxaliplatin plus fluoropyrimidine with or without cetuximab in the MRC COIN trial experience. $\mathrm{Br}$ J Cancer 2009; 100 (2): 251-8

25. Vermorken JB, Mesia R, Rivera F, et al. Platinum-based chemotherapy plus cetuximab in head and neck cancer. N Engl J Med 2008; 359 (11): 1116-27

26. Sobrero AF, Maurel J, Fehrenbacher L, et al. EPIC: phase III trial of cetuximab plus irinotecan after fluoropyrimidine and oxaliplatin failure in patients with metastatic colorectal cancer. J Clin Oncol 2008; 26 (14): 2311-9

27. Butts CA, Bodkin D, Middleman EL, et al. Randomized phase II study of gemcitabine plus cisplatin or carboplatin [corrected], with or without cetuximab, as first-line therapy for patients with advanced or metastatic non small-cell lung cancer. J Clin Oncol 2007; 25 (36): 5777-84

28. Cascinu S, Berardi R, Labianca R, et al. Cetuximab plus gemcitabine and cisplatin compared with gemcitabine and cisplatin alone in patients with advanced pancreatic cancer: a randomised, multicentre, phase II trial. Lancet Oncol 2008; 9 (1): 39-44

29. Bodey GP, Buckley M, Sathe YS, et al. Quantitative relationships between circulating leukocytes and infection in patients with acute leukemia. Ann Intern Med 1966; 64 (2): $328-40$

30. Boonstra J, Rijken P, Humbel B, et al. The epidermal growth factor. Cell Biol Int 1995; 19 (5): 413-30 
31. Raab G, Klagsbrun M. Heparin-binding EGF-like growth factor. Biochim Biophys Acta 1997; 1333 (3): F179-99

32. Herndon DN, Nguyen TT, Gilpin DA. Growth factors: local and systemic. Arch Surg 1993; 128 (11): 1227-33

33. Lewkowicz P, Tchorzewski H, Dytnerska K, et al. Epidermal growth factor enhances TNF-alpha-induced priming of human neutrophils. Immunol Lett 2005; 96 (2): 203-10

34. Lau J, Ioannidis JP, Schmid CH. Summing up evidence: one answer is not always enough. Lancet 1998; 351 (9096): 123-7

35. Thompson SG. Why sources of heterogeneity in meta-analysis should be investigated. BMJ 1994; 309 (6965): 1351-5
36. Higgins J, Thompson S, Deeks J, et al. Statistical heterogeneity in systematic reviews of clinical trials: a critical appraisal of guidelines and practice. J Health Serv Res Policy 2002; 7 (1): 51-61

Correspondence: Jian-hua Zhao, MD, Physical Examination Centre, the Jinan General Hospital of People's Liberation Army, 25 Shifan Road, Jinan 250031, People's Republic of China.

E-mail: jianhuazhao50@yahoo.com.cn

Zui Zou, MD, Department of Anesthesiology, Changzheng Hospital, Second Military Medical University, 415 Fengyang Road, Shanghai 200003, People's Republic of China.

E-mail: zouzui1980@yahoo.com.cn 